\title{
DESVENDANDO UM MISTÉRIO: A CANONIZAÇÃO DE AGATHA CHRISTIE NO BRASIL DURANTE OS SÉCULOS XX E XXI
}

\author{
Vanessa Lopes Lourenço Hanes
}

\section{A posição histórica de Agatha Christie no polissistema brasileiro de literatura traduzida: uma prova clara de que nada é assim tão simples}

Agatha Christie é conhecida mundialmente como uma autora de romances policiais bem-sucedida e prolífica, cuja carreira se construiu no decorrer do século XX. Por sua vez, os romances policiais são classificados tanto pelo público em geral quanto por críticos literários como literatura popular, periférica, ou o que se chama no meio acadêmico de literatura não-canônica. Porém, tal categorização não deve se dar de maneira assim tão simples, conforme este breve vislumbre da trajetória de Christie no Brasil irá demonstrar.

O objetivo aqui é compartilhar com o leitor a forma como as traduções de Agatha Christie no Brasil, publicadas entre a década de 1930 e os dias atuais, trilharam caminhos pouco convencionais e por vezes até conflituosos. Por um lado, os livros de Christie publicados no Brasil apresentam muitos sinais comuns à literatura canonizada, com um aumento diacrônico da evidência encontrada nesse sentido. Porém, esse suposto processo de canonização não ocorreu por meio dos métodos esperados, e talvez exatamente por isso ainda dê indicações contraditórias quando o status de Christie é considerado em um contexto mais amplo.

Agatha Christie surgiu no cenário brasileiro em um momento de grande relevância política e cultural. As primeiras traduções de suas obras foram feitas no início da década de 1930, mesmo período em que o primeiro regime ditatorial foi implantado no país pelo Presidente Getúlio Vargas. Essas traduções iniciais foram publicadas pela Editora Globo, então denominada Livraria do Globo, cuja sede situavase na mesma região geográfica do presidente em exercício: a cidade de Porto Alegre, Rio Grande do Sul. Coincidentemente (ou, muito provavelmente, nem tanto), a tradução mais antiga encontrada do livro O Assassinato de Roger Ackroyd (assinada por Heitor Berutti e datando de 1933) apresentava claros sinais de domesticação do texto, adicionando regionalismos gaúchos e dando certa cor local à obra de Christie. Talvez tal estratégia tradutória tenha sido utilizada como uma forma de conquistar a simpatia do 
Presidente Vargas — que, de acordo com Amorim (2000), era também amigo pessoal de alguns dos nomes mais influentes dentro da mesma editora. Porém, não foi possível até o momento encontrar evidências definitivas para reforçar tal suposição.

Muito provavelmente os livros de Christie foram aceitos para publicação no país naquele momento devido à sua natureza "inofensiva". Utilizando as palavras de Bargainnier, de modo geral o romance policial "é demasiadamente conservador, até reacionário em sua perspectiva social, política e moral" (1980, p. 10). ${ }^{1}$

E as evidências indicam que as obras de Christie não vieram desacompanhadas. $\mathrm{Na}$ verdade, no mesmo período o gênero romance policial como um todo foi introduzido no Brasil. Ele foi importado e transplantado na cultura brasileira como uma total novidade, e foi bem aceito provavelmente exatamente por ser tão diferente do que havia disponível no mercado literário da época. Even-Zohar indica que

O caso mais óbvio de importação parece ser aquele de trazer bens para cumprir certas funções que estão ausentes [...]. Ou seja, a importação pode ocorrer quando os bens importados não estão disponíveis no mercado local e um desejo de consumi-los é de algum modo despertado entre os membros de um grupo alvo. (Even-Zohar, 1997, p. $359)^{2}$

Esse novo gênero chegou às mãos do público brasileiro sem ter sido considerado por críticos literários, já que naquele momento ainda não havia forte tradição de crítica literária no Brasil voltada à literatura traduzida, e ainda menos de obras populares como as de Christie). O público foi o crítico que, de certo modo, iniciou Agatha Christie em sua jornada rumo à canonização.

O fato é que Christie aparece no cenário brasileiro em um período histórico quando a infraestrutura cultural da América Latina ainda sentia a falta e estava à procura de alguns itens culturais indispensáveis para a sua autoafirmação. Even-Zohar, ao discorrer sobre o papel desempenhado pela literatura no estabelecimento da Europa, afirma: "A literatura quase sempre figura, de uma forma ou de outra, entre os itens mais proeminentes" (1996, p. 45). ${ }^{3}$ E foi esse posicionamento estratégico, basicamente o

\footnotetext{
1 "is too conservative, even reactionary, in its social, political and moral outlook" (1980, p. 10. Tradução minha, assim como as demais citações extraídas de obras em língua inglesa).

2 "The most obvious case of import seems to be that of bringing in goods to fill in certain functions which are absent [...]. That is, import may occur whenever the goods that are imported are not available on the home market and a willingness to consume them is somehow aroused among the members of the targeted group."

3 "Literature almost always figures, in one form or another, among the most prominent items."
} 
estar no lugar certo e na hora certa, que parece haver determinado o destino de Christie dentro do polissistema literário brasileiro em um futuro próximo.

Isso não quer dizer, entretanto, que naquele momento o Brasil e a América Latina como um todo ainda se mantinham ingênuos com relação à questão da colonização cultural. Conforme coloca Rama (2004), os movimentos literários nacionalistas e particularmente os regionalistas estavam florescendo entre as décadas de 1920 e 1930, criando um clima de agitação no Brasil e na América Latina como um todo; e um dos pontos principais na agenda de tais movimentos era exatamente lutar contra os elementos estrangeiros historicamente impostos não somente na esfera literária, mas em todo o sistema cultural. No caso do Brasil, tais elementos de imposição eram também vistos como originários do Rio de Janeiro e de São Paulo, e forçados sobre os outros estados brasileiros. Assim, é importante apontar que a tradução de Christie mencionada acima e produzida no Rio Grande do Sul talvez não tenha sido simplesmente fruto de um "agrado" ao Presidente Vargas, mas constituído um reflexo da situação cultural no momento.

Esse exemplo serve para indicar desde já que a inserção de Agatha Christie no polissistema literário brasileiro foi realmente um caso multifacetado. E, após essa introdução, a questão da canonização em si será abordada utilizando exemplos que demonstram, por um lado, como Christie pode ser considerada uma autora canonizada no Brasil e, por outro, que talvez não seja correto simplificar demais o objeto de análise e situar Christie no mesmo patamar de outros autores canonizados.

\section{Cânone, canonizado, canonicidade: um panorama das diferentes perspectivas}

Antes de prosseguir, o conceito de cânone adotado no presente artigo precisa ser mais bem definido. Diferentes concepções e abordagens desse termo surgem de tempos em tempos, acrescentando novas dimensões a esta temática.

As palavras de Fowler podem ser usadas para iniciar a discussão, definindo o termo cânone em seu sentido mais estrito:

A literatura que criticamos e sobre a qual teorizamos nunca é o todo. No máximo falamos sobre subconjuntos significativos de escritores e obras do passado. Esse campo limitado é o cânone literário atual.

$[\ldots]$ 
O cânone fixo estabelece limites para a nossa compreensão da literatura, de diversas maneiras. O CÂNONE OFICIAL é institucionalizado através da educação, da patronagem e do jornalismo. (Fowler, 1979, p. 97-98) ${ }^{4}$

Entretanto, apesar de transmitir as premissas iniciais sobre o tema, essa forma de abordagem do cânone demonstra ser extremamente superficial em vista dos debates mais recentes. Um exemplo desses debates de maior profundidade é a abordagem de Guillory, que utiliza uma perspectiva bourdieusiana. Ele defende que

[o] conceito de capital cultural pode prover a base para uma nova explicação histórica do processo de formação de cânone e das condições sociais imediatas que dão origem ao debate sobre o cânone. Pois, apesar de, para os seus participantes, o debate parecer ser sobre o conteúdo do cânone literário, a sua importância vai além dos efeitos de qualquer novo consenso sobre um cânone verdadeiramente "representativo". O debate sobre o cânone significa nada menos do que uma crise na forma do capital cultural que chamamos de "literatura". (Guillory, 1994, p. viii)

O caso de Agatha Christie realmente servirá para demonstrar a existência de uma crise ou, ao menos, de uma mudança no que se entende por literatura no Brasil. Entretanto, a ideia de cânone adotada no presente texto tende a se alinhar mais com o ponto de vista polissistêmico, concordando com a posição de Even-Zohar (1990) quando este afirma que a literatura que é canonizada hoje não será necessariamente parte do cânone no futuro. Even-Zohar indica que as tensões entre literatura canonizada e não-canonizada são universais, e que o sistema canonizado sempre se encontra sob a ameaça de ser substituído pelo não-canonizado. O caso de Agatha Christie no Brasil é uma ilustração concreta de tal fenômeno.

Sela-Sheffy (1990) deixa claro quais os parâmetros da abordagem polissistêmica:

Se cânones são ordinariamente associados com "a tradição clássica", ou seja, com o que se acredita ser "a herança comum de textos valorizados no passado e no presente", a noção de "canonicidade" da Teoria dos Polissistemas é mais próxima daquela do que

\footnotetext{
4 "The literature we criticize and theorize about is never the whole. At most we talk about sizable subsets of the writers and works of the past. This limited field is the current literary canon.

$[\ldots]$

The fixed canon sets limits to our understanding of literature, in several ways. The OFFICIAL CANON is institutionalized through education, patronage, and journalism."

5 "the concept of cultural capital can provide the basis for a new historical account of both the process of canon formation and the immediate social conditions giving rise to the debate about the canon. For while the debate seems to its participants to be about the content of the literary canon, its significance goes well beyond the effects of any new consensus about a truly "representative" canon. The canon debate signifies nothing less than a crisis in the form of cultural capital we call "literature."
} 
"está na moda"; é um dos termos usados pela teoria para sugerir o privilégio de certos itens sobre outros (marginais ou antiquados) na literatura (ou em qualquer outra área cultural). Esta disparidade entre os dois conceitos ilustra mais tipicamente os traços especiais da abordagem sistêmica que a Teoria dos Polissistemas herdou do Formalismo Russo. (Sheffy, 1990, p. 513) ${ }^{6}$

Os casos utilizados como exemplo neste estudo são, em última instância, considerados nesse contexto polissistêmico. Porém, antes de partir para a discussão de casos específicos é necessário apresentar alguns esclarecimentos sobre o cânone brasileiro e a introdução de obras traduzidas no país como um todo, o que irá por sua vez auxiliar na compreensão dos exemplos extraídos da obra de Christie.

\section{O cânone brasileiro e a introdução de obras literárias traduzidas na cultura nacional}

Algumas obras literárias são quase que universalmente conhecidas pelos brasileiros com certa escolaridade, gozando de alto prestígio na cultura nacional. E essas obras que povoam o imaginário das massas são, em grande parte, também aquelas aceitas pela academia brasileira como o cânone literário da língua portuguesa. Amplas listas de autores e obras classificados por período histórico e acompanhados por análises detalhadas estão disponíveis no Brasil, tais como a didática Iniciação à Literatura Brasileira de Antonio Candido. A relevância e o amplo alcance de algumas dessas obras canonizadas no contexto cultural brasileiro serão demonstrados no presente estudo por meio de sua decisiva influência nas traduções de Agatha Christie. Machado de Assis, mencionado não só por Candido como por vários outros estudiosos como um dos maiores nomes do cânone literário nacional, será usado como ilustração desse fenômeno.

Em seu livro de 2003, Wyler compartilha informações essenciais sobre a dinâmica geral da introdução de livros traduzidos no país. Essa autora revela que até o princípio do século XIX nenhum livro era produzido no Brasil, e mesmo após esse período uma combinação de importações da Europa e altos impostos cobrados sobre a

\footnotetext{
6 "If canons are ordinarily associated with "the classic tradition," that is, with what is believed to be "the common heritage of past and present valued texts," Polysystem Theory's notion of "canonicity" is closer to that of the "fashionable"; it is one of the terms which the theory uses to suggest the privilege of certain items over other (marginal or out- dated) ones, in literature (or in any other cultural field). This disparity between the two concepts illustrates most typically the special accents of the systemic approach which Polysystem Theory inherited from Russian Formalism."
} 
produção local faziam da indústria literária um negócio muito pouco atrativo em território nacional.

Porém, a década de 1930 trouxe boas notícias para as editoras locais: a administração do Presidente Vargas começou a cobrar impostos pesados sobre os bens importados, inclusive obras literárias, o que por sua vez encorajou a maior produção de livros nacionais. E no mesmo período a censura do regime de certo modo serviu para abrir portas para a tradução literária, já que obras literárias traduzidas muitas vezes corriam menor risco de serem censuradas e por isso passaram a ser priorizadas pelas editoras. E foi assim que a literatura traduzida passou a ganhar espaço (e pouco a pouco também prestígio) no Brasil.

Nesse contexto a Editora Globo iniciou seu trabalho de tradução de muitos autores de língua inglesa, dentre os quais se encontrava Agatha Christie. A maioria das primeiras traduções de Christie foi lançada no mercado por esta editora. E é por isso que algumas de suas abordagens na tradução das obras de Christie no decorrer das décadas serão analisadas, juntamente com aquelas da Editora Nova Fronteira, que publicou o maior número de títulos de Christie no mercado brasileiro (particularmente na década de 1970).

\section{Alguns casos}

Três casos serão apresentados para esclarecer o porquê de afirmar-se aqui que Agatha Christie tem gradativamente se tornado parte do cânone de literatura traduzida no Brasil. O primeiro caso mostra como o uso da língua nas traduções de Christie apresenta compatibilidades com aquele encontrado em obras previamente canonizadas no país. O segundo exemplo ilustra o percurso de suas traduções desde quando eram publicadas em coleções de livros populares até o momento atual, em que são incluídas lado a lado com obras canonizadas da literatura mundial. E o terceiro caso a ser utilizado como exemplo demonstra como Christie tem, inclusive, ganhado espaço no sistema educacional brasileiro.

Por fim, um momento antagonista será introduzido neste estudo: um quarto exemplo servirá para desconstruir a visão simplista e linear que, talvez, possa ser ilusoriamente incentivada pelos primeiros três casos, demonstrando que Christie não se encontra em pé de igualdade com os principais nomes que hoje são considerados literatura canonizada no polissistema literário brasileiro. 
HANES - A canonização de Agatha Christie no Brasil durante os séculos XX e XXI

\subsection{Escolhas linguísticas em traduções de Agatha Christie: o caso de Leonel Vallandro}

Apesar de este texto ter como base as diretrizes descritivas estabelecidas por Lambert e van Gorp (1985), a ordem sugerida por estes autores será invertida, optando por iniciar a análise com exemplos em nível microtextual da canonização de Agatha Christie no Brasil. Tal escolha foi feita para apresentar os dados ao leitor diacronicamente, em um crescendo.

Nesse sentido, as primeiras indicações de como as obras de Christie foram abordadas de forma semelhante ao que se fazia com obras já canonizadas são encontradas já no princípio da história desta autora no Brasil, em instâncias em nível micro (ou seja, no uso de elementos textuais tais como itens lexicais) encontradas em diferentes traduções, dentre elas aquelas feitas por Leonel Vallandro, tradutor responsável pelo primeiro caso analisado.

A trajetória de Vallandro como tradutor está intimamente ligada à história da Editora Globo, a qual o contratou provavelmente na década de 1940 em tempo integral. Dentre os quase trinta títulos encontrados traduzidos por Vallandro para a Globo (o número total possivelmente é muito maior, já que há pouca informação disponível), há dois livros de Christie. O primeiro caso analisado aqui é o uso da língua portuguesa em um destes livros, a saber, O Assassinato de Roger Ackroyd.

Essa tradução de Vallandro foi publicada em 1951. Ela foi precedida por uma tradução já mencionada anteriormente, feita pelo jornalista gaúcho Heitor Berutti em 1933, e que conforme já exposto apresentava coloquialismos e características regionalistas. Entretanto, o trabalho de Vallandro adota uma postura bem diferente.

O fato é que o uso da língua portuguesa na tradução de Vallandro aparenta ser consistente com aquele encontrado em obras literárias nacionais anteriores e já bastante prestigiadas. Como resultado, a tradução brasileira de um livro que originalmente utiliza um estilo informal acaba por ter um registro, ou seja, um uso da língua, muito mais rebuscado. Este registro alto é determinado pelo uso de certas estruturas gramaticais e pelo uso de vocabulário em geral. Um exemplo de uma tradução de Vallandro é apresentado abaixo, e o original em inglês também é fornecido para permitir comparação:

- Ralph e eu nos separamos pouco antes das nove e três quartos. Êle não se aproximou da casa, disso tenho plena certeza. E não tencionava fazê-lo; tudo teria feito naquela noite, menos enfrentar o padrasto. (p. 236) 
"Ralph and I parted just before a quarter to ten. He never went near the house, I am sure of that. He had no intention of doing so. The last thing on earth he wanted was to face his stepfather." (p. 282)

A escolha de palavras em geral demonstra a diferença de estilo, com maior formalidade no português: o formato usado para dizer as horas, o uso de ênclise, a escolha de palavras tais como "tencionava". Ademais, a inversão da ordem das palavras no trecho em itálico colabora para dar um ar poético ao texto. O personagem falando aqui é Úrsula, uma empregada doméstica com certo nível educacional, porém nada que se compare com aquilo que fica implícito nesse discurso atribuído a ela em português.

O uso recorrente de palavras específicas adotadas por Machado de Assis mais de cinquenta anos mais cedo (termos tais como "alvitre", encontrado repetidamente em Dom Casmurro e no discurso direto dos personagens nesta tradução de Vallandro, embora não fosse parte do discurso coloquial em português brasileiro daquele momento histórico) indica que Christie foi traduzida no Brasil com claras similaridades com a literatura canonizada do país.

\subsection{A inclusão de Agatha Christie em coleções: ontem publicada com Ellery Queen, hoje publicada com Platão}

Outro sinal claro de como Agatha Christie tem passado por um processo de canonização no Brasil é a sua inclusão gradual em diferentes coleções de livros com diferentes formatos no decorrer do tempo.

De acordo com um estudo detalhado desenvolvido por Amorim (2000) sobre a história dos primórdios da Editora Globo, Agatha Christie inicialmente foi publicada em coleções com seus semelhantes, ou seja, com outros autores de romances policiais populares tais como Ellery Queen, Edgar Wallace e George Simenon, em uma coleção especial chamada de Coleção Amarela. ${ }^{7}$ Esses livros de bolso eram produzidos no formato mais barato possível, em papel jornal. Um exemplo pode ser observado na Figura 1.

\footnotetext{
${ }^{7} \mathrm{O}$ formato e o próprio nome desta coleção parecem ter sido inspirados pela abordagem europeia do gênero romance policial. Por exemplo: os romances policiais publicados na Itália no mesmo período histórico também têm capas amarelas e são universalmente conhecidos como giallos (amarelo em italiano). Romances policiais são apresentados em formato com capas amarelas em muitos países europeus.
} 


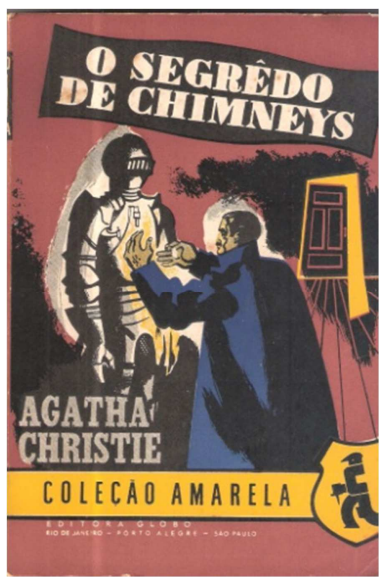

Figura 1. Capa de um livro de Agatha Christie publicado na Coleção Amarela em 1948.

Entretanto, uma vez que as editoras perceberam que Christie era um verdadeiro sucesso no Brasil, essa autora se tornou mais prestigiada e começou a ter suas próprias coleções editadas. Muitas versões da Coleção Agatha Christie vieram a existir, lançadas por diferentes editoras: Editora Globo, Editora Record e Editora Nova Fronteira investiram fortemente na produção de novas edições das traduções de Christie no país. A qualidade das cópias físicas também melhorou consideravelmente: papel branco passou a ser utilizado para a impressão dos textos, e mesmo o formato de bolso foi abandonado por certo tempo. Record e Nova Fronteira também investiram em versões de capa dura das coleções de Agatha Christie. Seguem abaixo alguns exemplos de capas de diferentes coleções tendo como foco exclusivo as obras de Christie.
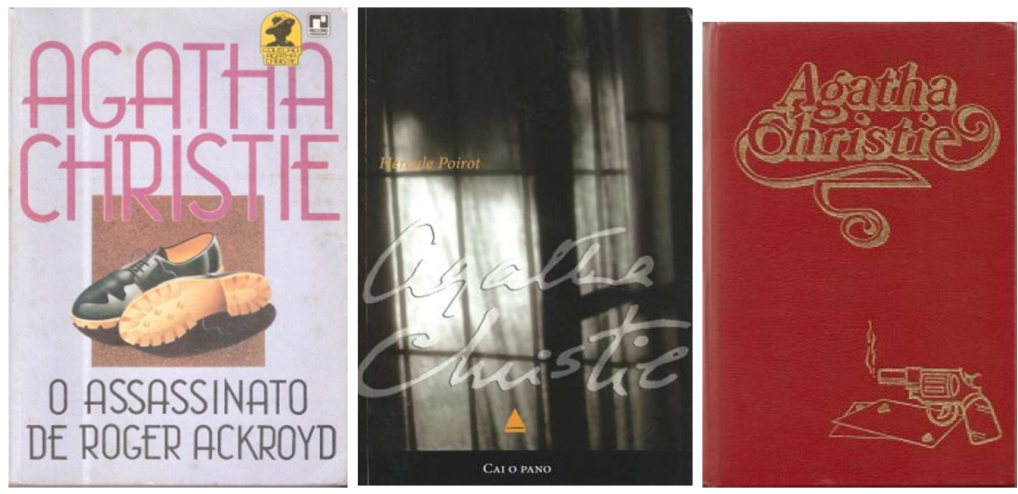

Figura 2. Capas de algumas coleções de obras de Agatha Christie publicadas no Brasil

O passo mais recente da inclusão de Christie em uma coleção literária, entretanto, serve como fator decisivo para demonstrar como sua importância no Brasil cresceu ainda mais nos últimos anos. Em 2011, pela primeira vez Christie foi publicada em uma nova série lançada em conjunto pela Editora Nova Fronteira e pela Livraria 
Saraiva. E nessa nova coleção o até então inimaginável se tornou realidade: Christie foi publicada lado a lado com autores brasileiros canonizados tais como José de Alencar e Machado de Assis, bem como lado a lado com nomes canonizados mundialmente tais como Platão, Maquiavel, Shakespeare e outros. Inclusive a capa de cada livro é personalizada, e autores com mais de um livro na mesma coleção (como no caso de Christie) têm diferentes caricaturas inseridas na capa de cada título.
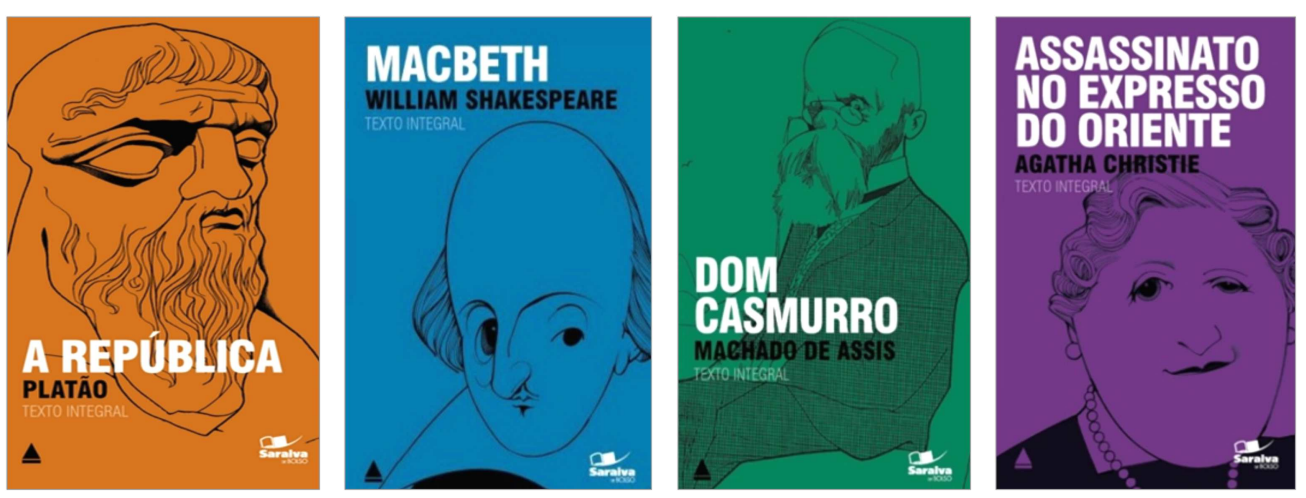

Figura 3. Capas da Coleção Saraiva de Bolso

Esse exemplo insinua que Agatha Christie não poderia ir mais alto no cânone literário brasileiro com relação ao seu prestígio e à sua classificação entre os autores internacionais publicados no Brasil.

\subsection{Suplementos de leitura: das bancas para as salas de aula}

O terceiro caso que demonstra como Christie vem cada vez mais sendo tratada enquanto cânone no polissistema literário brasileiro é o fato de que, pelo menos desde 2000, a Editora Globo tem publicado suplementos de leitura em todas as edições dos livros de Christie.

Estes suplementos de leitura são desenvolvidos por professores da área de Letras ligados a instituições educacionais brasileiras e têm como objetivo ser utilizados com adolescentes em idade escolar, em aulas de literatura. As atividades propostas vão desde compreensão de texto até escrita de redações, incluindo ainda leitura complementar recomendada e questões para reflexão e debate. 


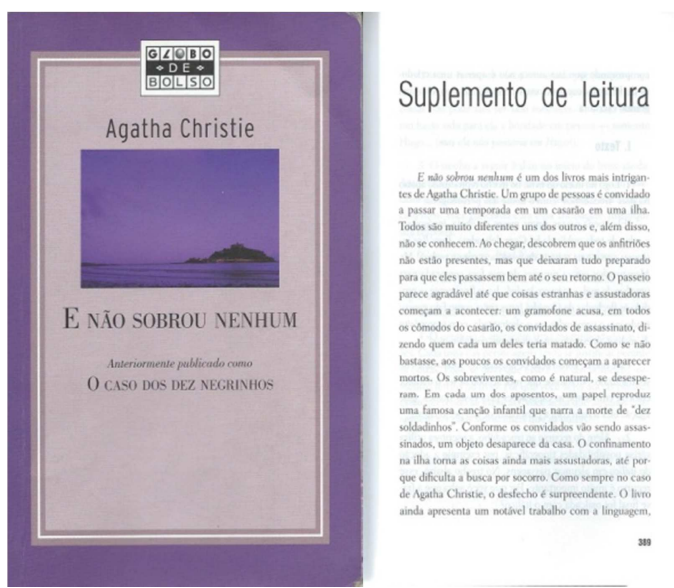

Figura 4. Capa da tradução brasileira do livro And Then There Were None e a primeira das nove páginas de um suplemento de leitura publicado dentro do mesmo livro (Editora Globo, 2008)

Este terceiro exemplo demonstra como Christie tem sido canonizada mesmo no sentido mais estrito do termo cânone, já que Fowler afirma que a educação é um dos meios de reforçar a canonização em uma cultura.

\subsection{Quando o conhecimento enciclopédico se torna necessário: o que a Enciclopédia Barsa tem a dizer}

Após os três casos utilizados para defender a canonização de Christie no Brasil, chega o momento de expor o último caso a ser analisado que, por sua vez, demonstra que a posição ocupada por Christie no Brasil não é tão bem estabelecida.

Enciclopédias são um bom termômetro para medir a importância de certos tópicos dentro de determinada cultura. E um dos tópicos que pode ser medido utilizando este recurso é a presença de determinado autor e a sua importância em certo polissistema literário. Desse modo, a obra de Agatha Christie foi testada de uma maneira bastante simples, utilizando uma das enciclopédias mais populares do Brasil: a Enciclopédia Barsa.

Essa enciclopédia ainda é alvo de grande confiança enquanto fonte de conhecimento no país, e recentemente foi disponibilizada em formato digital online. $\mathrm{O}$ teste feito aqui foi breve, procurando responder às seguintes perguntas: quantas entradas conectadas com o nome de Christie foram encontradas nessa enciclopédia? E quantas entradas foram encontradas em conexão com alguns dos outros nomes publicados lado a lado com Christie na Coleção Saraiva de Bolso, mencionada em um dos exemplos acima? 
A resposta serve para ilustrar de modo mais claro o status controverso de Christie no Brasil. Foi encontrada somente uma entrada para o nome de Agatha Christie no site da enciclopédia, uma conexão para uma nota biográfica. Por outro lado, Machado de Assis tinha oito entradas associadas ao seu nome, contemplando temas como prêmios literários, crítica literária, além de suas obras individuais. Havia sete entradas ligadas ao nome de William Shakespeare, uma delas associando seu nome à gênese do teatro moderno. Platão, por sua vez, resultou em cinco entradas de documentos associados às suas obras filosóficas. E, trazendo o debate para uma esfera mais próxima de Christie, quatro entradas foram encontradas para o autor de romances policiais Arthur Conan Doyle (criador de Sherlock Holmes).

A evidência aqui mostra claramente que, apesar de Christie ser colocada lado a lado com tais autores, e ser considerada uma autora digna de utilização em aulas de literatura, seu status enquanto parte do cânone não é inquestionável, embora também não possa ser negado.

\section{Algumas conclusões: a canonização de Agatha Christie e o seu impacto na dinâmica cultural brasileira}

Todos os exemplos analisados servem para indicar que o caso de Agatha Christie é uma história complexa, cheia de possibilidades para maior investigação e comparação com outros casos semelhantes. Apesar de quatro exemplos envolvendo editoras e tradutores específicos não poderem ser considerados representantes da totalidade das obras de Christie no Brasil, eles ao menos revelam uma situação sintomática com claras áreas de conflito.

Parece seguro dizer que a abordagem em nível micro escolhida para a tradução de Christie no início de sua propagação no país, exemplificada aqui pelas escolhas tradutórias de Vallandro, pode ter tido papel decisivo na forma como Agatha Christie foi incorporada no polisssistema cultural brasileiro. Em termos simples, a hipótese proposta é que, se um livro traduzido soa como um texto escrito por um autor canonizado e bem-estabelecido no mercado editorial local, aparentemente há uma chance muito maior de este livro traduzido alcançar posição e prestígio elevados na cultura alvo. Já que o texto de Assassinato no Expresso do Oriente soa como Machado de Assis, essa tradução feita por Archibaldo Figueira (cujas estratégias tradutórias se 
assemelham àquelas usadas por Vallandro no que se refere à elevação do registro $)^{8}$ pode perfeitamente ser publicada em uma coleção lado a lado com Machado de Assis, sem nenhuma inconveniência para o público ou para a editora, como ocorreu na Coleção Saraiva de Bolso. Ademais, se o mesmo livro soa como Machado de Assis, por que não ir em frente e incluí-lo nas aulas de literatura para as crianças e adolescentes em fase de aprendizagem da língua portuguesa? O livro foi formado nos moldes da literatura canonizada, e seguiu o curso natural, a saber, ser tratado como tal.

Entretanto, em outro extremo está o quarto exemplo mencionado para lembrar o leitor de que as coisas nem sempre são "preto ou branco". Nem sempre é possível ser simplesmente isto ou aquilo, e no caso de Christie realmente há muitos elementos intermediários que poderiam (e deveriam) ser examinados de forma mais aprofundada. Sua presença ainda não-consolidada no chamado "conhecimento enciclopédico" indica uma posição ainda não-canonizada no polissistema literário brasileiro. Muitos sinais apontam para um lugar sistêmico mais privilegiado para esta autora no futuro, mas a curiosa situação de "semi-canonização" de Christie merece ser observada de perto por pesquisadores de diferentes áreas. Afinal, a canonização de um autor se dá, em grande parte, atrelada à academia, e percebe-se que a presença de Christie no âmbito acadêmico ainda é bastante restrita. Quando se fala em Agatha Christie nesse meio, normalmente tal menção se dá no contexto de pesquisas sobre o gênero romance policial, e não sobre Agatha Christie e sua obra em si. Livros sobre Shakespeare ocupam muitas estantes de qualquer biblioteca, mas e os livros sobre Christie, uma campeã absoluta de vendas por décadas? Costumam ser escassos e pouco interessantes. Esses curiosos contrastes demonstram que muita investigação será ainda necessária para desvendar completamente as diferentes nuances da presença de Agatha Christie no mercado editorial brasileiro.

\section{Referências}

AMORIM. S. M. de. Em Busca de um tempo perdido: edição de literatura traduzida pela Editora Globo (1930-1950). São Paulo: EDUSP, 2000.

\footnotetext{
${ }^{8}$ Um exemplo da elevação do registro nesta tradução seria a utilização recorrente do pretérito-mais-queperfeito para a tradução do discurso do personagem norte-americano MacQueen. Como de costume nas obras de Christie ao retratar norte-americanos, MacQueen utiliza um inglês mais coloquial do que o apresentado pelos personagens britânicos do original, o que se perde totalmente nas opções tradutórias adotadas por Figueira. Para mais detalhes, ver Hanes (2014).
} 
HANES - A canonização de Agatha Christie no Brasil durante os séculos XX e XXI

BARGAINNIER, E. F. The gentle art of murder: the detective fiction of Agatha Christie. Bowling Green: Bowling Green University Popular Press, 1980.

CANDIDO, A. Iniciação à Literatura Brasileira (resumo para principiantes). São Paulo: Humanitas, 1999.

CHRISTIE, A. O Assassinato de Roger Acrkoyd. Trad. Leonel Vallandro. Porto Alegre: Editora Globo, 1970.

The Murder of Roger Ackroyd. New York: Dodd, Mead \& Company,1926.

ENCICLOPÉDIA Barsa. Disponível em: <http://brasil.planetasaber.com/search/results.asp>. Acesso em: 08 set. 2014.

EVEN-ZOHAR, I. Polysystem theory. Poetics Today, Durham, v.11, n.1, p. 3-26, 1990.

The Role of Literature in the Making of the Nations of Europe: a SocioSemiotic Study. Applied Semiotics/Sémiotique Appliqué, v. 1, n.1, p. 39-59, 1996. Disponível em: <http://french.chass.utoronto.ca/as-sa/ASSANo1/Vol1.No1.EvenZohar.pdf>. Acesso em: 08 set. 2014.

. The Making of Culture Repertoire and the Role of Transfer. TARGET International Journal of Translation Studies. Amsterdam/Philadelphia: John Benjamins, v. 9, n.2, p. 355-363, 1997.

FOWLER, A. Genre and the Literary Canon. New Literary History. V. 11, n. 1, p. 97 119, $1979 . \quad$ Disponível em: $<$ http://www.unife.it/letterefilosofia/lm.lingue/insegnamenti/letteratura-inglese-iilm-lingue/programma-bibliografia-calendario-lezioni-modalita-desame-emateriale-didattico-anno-accademico-2012-2013/Alastair\%20Fowler\%20Genre\%20and\%20the\%20Literary\%20Canon-\%201979.pdf>. Acesso em: 16 ago. 2014.

GUILlORY, J. Cultural capital: the problem of literary canon formation. Chicago: The University of Chicago Press, 1994.

HANES, V. L. L. As traduções de Agatha Christie no Brasil: considerações sobre a representação da oralidade e o pós-colonialismo. Mutatis Mutandis. v. 7, n. 2, p. 306-333, 2014. Disponível em: $<$ http://aprendeenlinea.udea.edu.co/revistas/index.php/mutatismutandis/article/vie w/19011/17407>. Acesso em: 27 abr. 2015. 
HANES - A canonização de Agatha Christie no Brasil durante os séculos XX e XXI

LAMBERT, J.; GORP, H. van. On describing translations. In: HERMANS T. (Ed.). The manipulation of literature: studies in literary translation. London/Sidney: Croom Helm, 1985. p. 42-53.

RAMA, Á. Transculturación narrativa en América Latina. México: Siglo XXI Editores, 2004.

SELA-SHEFFY, R. The concept of canonicity in Polysystem Theory. Poetics Today. V. 11, n. 3, p. 511-522, 1990.

WYLER, L. Línguas, poetas e bacharéis: uma crônica da tradução no Brasil. Rio de Janeiro: Rocco, 2003. 